\title{
Resistance to Opportunities of Plastic Recycling
}

\author{
Weiling He, Astrid C Layton, Terry S Creasy, and Alejandro Borges
}

\begin{abstract}
Plastics present a vast and pressing issue in modern society. Currently, recycling efforts fall dangerously short and cannot deal with even a small percent of the millions of tons of plastic waste produced yearly across the globe. This article investigates resistance toward plastic recycling in three areas from both a contemporary and a historical context, highlighting the problem's magnitude and the current solution's inadequacy. This article covers the plastics problem from (1) a design perspective, (2) a material science perspective, and (3) a systems perspective. Solutions are proposed that emphasize a synergistic collaboration across disciplines and research modes. Ultimately, the conclusions point to a need for stronger engagement at the level of people (both consumers and decision makers) and reintegrating reused and recycled plastics into everyday life to build a solid foundation for success.
\end{abstract}

Keywords: Materials, Plastics, Systems-Perspective, Bio-Inspired Design.

\section{Introduction}

Plastic recycling is a critical but unresolved issue for our living environment. Over the last ten years, we have produced more plastic than that produced over the last century. It takes 500 to 1,000 years for plastic to degrade and remains toxic even after degrading. According to Yale Environment 360, the US generated more than 42 million metric tons of plastic waste in 2016, the highest volume in the world (Yale Environment 3602020 ). although the US holds only $4 \%$ of the global population, it produces $17 \%$ of all plastic waste globally. Thus, during the 2020 America Recycles Summit, the US Environmental Protection Agency (EPA) announced a national recycling goal: increase the US recycling rate to $50 \%$ by 2030 (EPA 2019). This new national goal will provide the foundation to evaluate success in the collective efforts to improve the recycling system in the US.
In the past fifteen years or so, artists, designers, and engineers have been raising the public's awareness of disposable plastics and to find strategies to recycle them. The plastic recycling field intersects creative disciplines. To our surprise, however, research about plastic recycling has not advanced much other than in making plastic lumbers and synthetic fibers. Plastics seem to have turned from a ubiquitous material permeating our everyday life to a dispensable option once recycled. Smooth and shiny fresh plastic objects are alluring, they make us feel our lives have quality, vibrancy, affordability, and convenience. When they are recycled, all these attractive qualities seem to be lost. The vibrant colors become gloomy grey; the cost to recycle can be much higher than making new plastics; and convenience is gone. What makes it worse is that polymer research is gradually losing its appeal to material scientists as the focus has shifted to nanotechnology.

Stable URL: https://arcc-journal.org/index.php/arccjournal/article/view/1098 DOI 10.17831/enq:arcc.v16i2.1098

Corresponding Author: Weiling $\mathrm{He}<$ weiling.he@tamu.edu $>$

Published by the Architectural Research Centers Consortium under the terms of the Attribution-NonCommercial-ShareAlike 4.0 International license 
The contrast between the urgent need for recycling plastics and the delay in making substantial development is highlighted by current fast-paced technological innovations. In fact, such contrast reveals that innovation is misunderstood to mean "making something new" (Tanenbaum 2016). This view maintains that when the new is created, the old will be replaced and disposed of. This disposal mentality is exactly what has caused rampant plastic pollution on earth. Ironically, plastics as chemical composites can never be eliminated once produced but can only be transformed or reused.

Why the delay in advancing plastic recycling? This paper will investigate the resistance to plastic recycling from multiple angles, such as design, material science, cost and policy, and system-level analyses. The objective is to identify critical touchpoints that reinforce the resistance so that critical changes can be implemented to transform the resistance to attraction.

\subsection{A DESIGN PROBLEM}

This image showing shoes made from plastic bottles sends a powerful message about repurposing recycled plastics. The design is clever: plastic bottles are durable material; they are crushed into double layers, increasing the durability; water bottle neck is used to tie the straps; and the grooves on the bottle neck keep straps in place. The image is also emotionally charged: the textures of the rough skin, the soiled bottles, and the sand scream survival. Perhaps we can learn two critical aspects about plastic recycling as a design problem: the design needs to be useful, and the material quality needs to be polished.

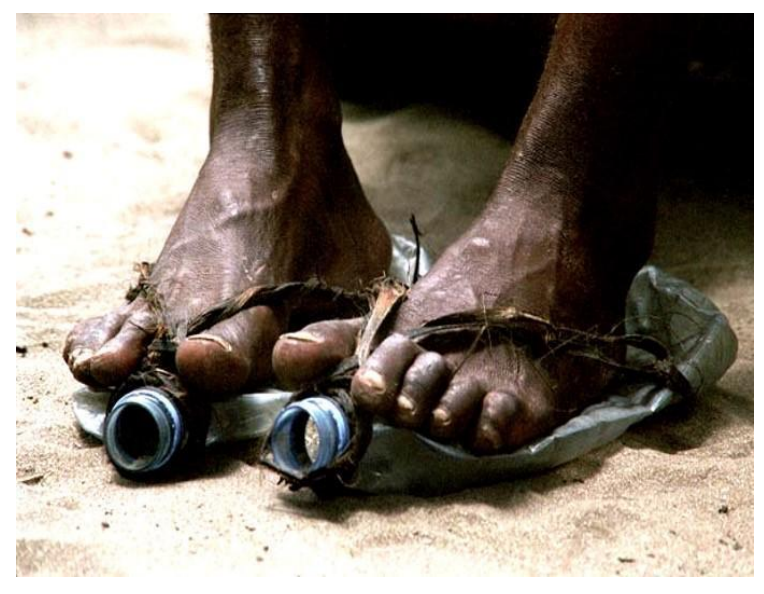

Figure 1. Repurposed plastic bottles (Casado 2018).
In the arts, a field close to design, making projects with plastic objects seems to be successful. Art projects, creating the illusion of polish or overtly denying the need for polish, came to the forefront, promoting the concept of plastic recycling. Tara Donovan's works, such as Logical Conclusions (2005), Untitled (2006), and Untitled (2007), resemble topological landscapes and biomorphic processes and are composed of everyday objects. Jean Shin's Sound Waves (2007) literally presents a wave of vinyl records. Chris Jordan's Gyre (2009), a plastic reinterpretation of "Great Wave off Kanagawa," creates a blunt link between our everyday plastic waste and the sea. Sayaka Ganz's Material Afterlife (2009) turns household plastic into a frozen moment of moving animal bodies. Each of these artists' works inspire the public to look at disposable plastic objects in a new light.

These visually appealing artworks derive from transforming materiality from everyday objects to an expressive overall appearance. Such transformation happens in perception, simultaneously presenting contrasting attributes in the same material, such as soft and hard, light and heavy, and flat and volumetric. The audience discovers these contrasts when shifting their perceptive scales. In the object's scale, its geometry is tied to its functional meaning and structural integrity: a plastic cup has a rim, a wall, and a bottom to fulfill functions: containing fluid, being held, and being drunk from. Increasing the amount, pattern, and repetition of the cups reduces the object's scale to a spot. As in Tara Donovan's work, thousands of plastic cups connected together resemble soft clouds where an overall curvature of the collective form is emphasized. The appearance of the work

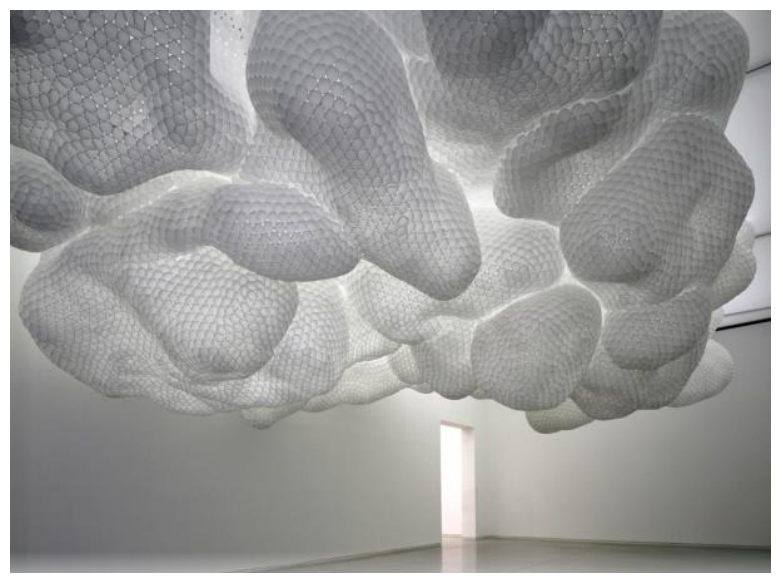

Figure 2. Untitled by Tara Donovan made of plastic cups (Donovan 2006). 
and the fluidity of the curves overrides the imperfections of joints among the cups or the cuts of the holes.

As opposed to its use in artwork, recycled plastic does not seem to possess the aesthetic quality that consumers desire in the design field because the scale of an object is never reduced to a spot. When designing a new object with recycled plastic, materiality is examined in the same way as a plastic cup. If the manufacturing precision was less than what a plastic cup possesses, the new object made from recycled plastic would appear less valuable. The same rule applies to an individual's effort in repurposing plastic objects. If lacking precision in making, one's enthusiasm in repurposing plastics will cease at overly simplified and coarse products. So many underdeveloped projects with recycled materials have been produced that "recycled art" gradually becomes a synonym of trash art, both a literal (the material) and a metaphorical (the value) sense.

Although innovations have been made-engineering portable plastic recycling systems, integrating plastic recycling in the local tourist economy, and structural speculations of the strength of water bottles-the fundamental design problem has not been resolved. Recycled plastics still do not look refined. In the area of portable engineering, Dave Hakkens' Precious Plastic Project aims "to provide people the tools to start working with plastic waste locally" (Hakkens 2013). Having started assembling the logo "Precious Plastic" with plastic waste and leftover plastics, Hakkens has been on an intense journey since early 2013. He developed and launched two versions of a modular plastic recycling system, made the recycling system an online open source for a wider audience to access, and traveled to underdeveloped areas, such as Kenya, Mexico, India, and Bali, to help local people build their own recycling systems. Hakkens made small-scale objects, such as lampshades and vases, from the recycling system. These objects become sample designs for people to envision the end products of plastic recycling. However, the polished-ness is challenging to achieve. Containers produced from Hakken's workshop are intriguing to look at but lack the refinement of even a solo cup. They are precious only in a semantic sense.

Lionel Taito-Matamua and his professors, Simon Fraiser and Jeongbin Ok, at Victoria University of Wellington in New Zealand, contextualized plastic recycling in the local indigenous culture. Taito-Matamua's own heritage has strong ties to Samoa. Inspired by the world's first RecycleBot, which recycles 3D printing waste into reusable filament for the printers, by Victoria University of Wellington, Taito-Matamua engineered ways to combine plastic water bottles and coconut fibers in 3D printing filament to print souvenirs for tourists. The project addressed multiple issues around the negative impact of tourism to Samoa, such as disposal of plastic water bottles, damage to rare species from the demand of souvenirs, and the stagnant economy of the local indigenous population. It is unique in its own context and thus challenging to expand and serve as a model on a larger scale. The preciousness of the object made from recycled plastic results more from the story behind the making process than in its materials and craft's own right.

Trussfab integrated computer software development and 3D printing to design and construct truss structures with plastic soda bottles (Kovacs 2018, 2019). Truss-Fab's "converter" software transforms a threedimensional digital model into a honeycomb structure and edits it to a desired form. Based on the form, Truss-Fab's "hub generator" software creates connectors for 3D printing and laser cutting. These connectors combine soda bottles into a large truss structure. Integrating structural calculations, the truss structure can hold human weight so that they can be parts of furniture, such as chairs and tables. Presented at CHI'17 in Denver, the most recently constructed large-scale structure was 5 meters tall and consisted of 1280 bottles and 191 3D printed hubs. The concept of this effort seems inspiring, but the efficiency and durability of making a large structure with plastic bottles remains questionable. Furthermore, health and safety issues may rise when such a structure is to be integrated in a consumer's everyday life.

Some world-renowned businesses who produce plastic waste have tried to play a role in advocating plastic recycling. For example, as a marketing strategy in Vietnam, Coca Cola offered upcycling kits alongside Coke drinks in 2014. With this simple twist, waste Coke bottles were repurposed into useful objects and not thrown away. A short video showed happy kids and elderlies having attached a connector to empty Coke bottles and transformed them into a water gun, a magic marker, a night light, a spray bottle, a bubble blower, a pencil sharpener, and a barbell. The smiles on these people's faces are priceless. However, one may have reasons to think this is merely a PR gesture as questions remain unanswered. The company who manufactures the connectors used new plastics to 
make these connectors. Where is the recycling? What happens when these new objects repurposed from Coke bottles become worn? How many of these objects does one need compared with one's Coca Cola consumption and the massive number of bottles supporting that consumption?

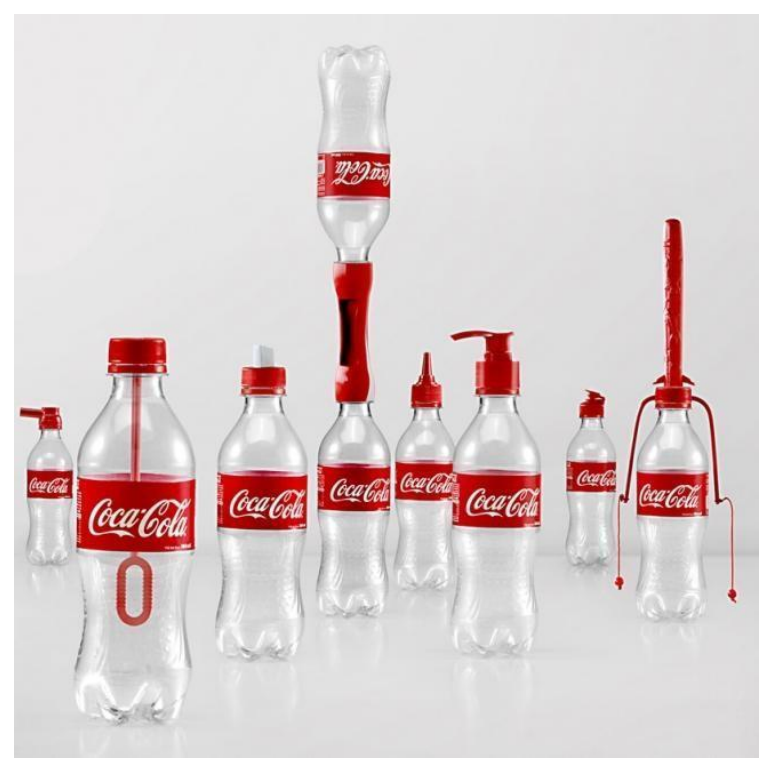

Figure 3. Coke bottle adaptors (Sora News24 2014).

To truly recycle plastics, we must reintegrate the new product in people's everyday lives. We must reduce our everyday plastic needs so that recycled plastic, i.e. plastic that is already in circulation, is able to satisfy our plastic consumption. We also have to honestly accept the qualities of objects that we naturally desire. Make-do projects that satisfy human survival needs at a very basic level, such as walls made from plastic water bottles to increase natural ventilation or flotation devices made of plastic bottles or jugs, are far from sustaining human's aesthetic desire. For example, tapestry woven from plastic threads cannot exceed the quality of other woven materials, such as wool and silk. The world-renowned Canadian architect/artist Phillip Beesley admitted in a workshop that, compared to transparent and shiny new plastics, the grey appearance of recycled plastic was still a less desirable material, even though his work mimics and advocates a sustainable system of living creatures. Rawness and refinement are never absolute-one can identify refinement in a piece of raw pebble polished by tides-so the objects made from recycled plastic need to achieve a common definition of refinement in order to be accepted by the general public. The obstacles in designing with recycled plastics points at the plastic material: is there a way to make recycled plastic with desired material quality?

\subsection{A MATERIAL SCIENCE PROBLEM}

The plastics that are a challenge for the cyclic economy are the products from chemistry and materials science research for the last 100 years. People considered these materials as almost miraculous because their unique molecular weight provided-for that time-novel functions in processing and performance. Current plastics technology produces plastics that are inherently difficult to recycle. New plastic arrives in small flakes or pellets that machinery can convey into a process that converts them into large, shaped structures (Cunha 2009). Those structures (bottles, bins, electronics enclosures, etc.) must be torn down into fine particles; this recycling step cannot be eliminated.

With hindsight-much like the polluted region in low-earth orbit-we know now that allowing these materials unfettered production, use, and disposal was building a problem that this generation must address. The fundamental material science issues about polymer recycling are polymer mingling and contamination. When we mingle polymers - specifically polymers incompatible by either processing temperature range or chemistry-we turn a cyclic economy resource into a waste stream. Further, non-polymer contaminants, for example metals, soil, or paper, can affect properties in recycled components or ruin a process run and lead to electricity generated by polymer used fuel or the components being discarded into a landfill (Eriksen 2018, Flizikowski 2021).

In societal discussions, we call these materials "plastics," but "polymer" is a more precise term for high molecular weight carbon-chain materials because many materials can deform plastically. Three recycling/cyclic economy waste streams are emerging. First, and worst from a cyclic economy stance, is a fully mixed waste stream (Möllnitz 2021). Total mingling for the household waste stream requires extensive separation, cleaning, and physio-chemical characterization prior to reprocessing. This source stream leads to "downcycling," which means the materials and goods produced have limited application because the recycled material properties are significantly lower than polymer products made from unspoiled petroleum sources. However, the performance from downcycled materials is still valuable and might be 
acceptable if we look at the applications with a fresh viewpoint.

The second waste stream comes from targeted recycling, for example bins that receive specific polymers, metals, and paper presorted by consumers before collection. However, consumers can still mis-deposit materials or misuse the containers, making inspection and sorting necessary anyway. Finally, the third waste stream comes from the manufacturing centers that process products made from new polymers. Many producers directly use the waste they generate by grinding the waste and mixing it with the new material supply at fractions reaching 10 percent or higher. At this level, recycled polymers can form first-level products, including products that contact food and drink (Cecona 2021).

Every polymer waste stream can contribute to cyclic use, with downcycled materials becoming available as a new material class that still contributes to economic development. Issues in adopting these materials depend on the country where the products become discarded. For example, in places where there is low economic development, polymer waste might be fuel for electric generation unless the economy can grow to include reprocessing. Alternately, where industry produces polymers the new material supply might make recycling less attractive (Silva 2020).

Each world region-from material producing to material consuming-needs a consistent goal-orientated approach to support cyclic use. Material producers and suppliers should move beyond internal feedstock reuse to incorporate an outreach process that supports local, regional, and world resupply paths. Lower-level economies should receive aid to build a network that resists burning polymers for energy consumption, which wastes a valuable material by destroying the carefully produced properties forever while adding pollutants to the air. Initial processes in non-material producing economies should take a first approach-collection, sorting, cleaning, shipping to a reprocessing economy-and receive aid to build a long-term approach-reduce shipping by building a local recycling program. The early-stage recycling could ship the recycled feedstock to produce economies. In future stages, the local economy could grow into a producing region with supplies fed with the locally recovered polymer. The effects from establishing a local/global system could cut waste release substantially.

Costs associated with recycling range from minor (e.g., when a plastic component producer immediately recycles their new waste into further new products) to major (e.g., when post-consumer plastics are mixed with other materials in a recycling bin, or at worst, mixed in with all household waste). Whether presorted as a bin containing "recyclables" or mixed in general trash, the first step is manual sorting by workers. The workers face difficult conditions. They must work to pull specific materials from a moving conveyor efficiently, separating polymers from metals and paper, and polymers from similar, incompatible polymers. Figure 4 shows that plastics waste falls into at least 7 major categories.

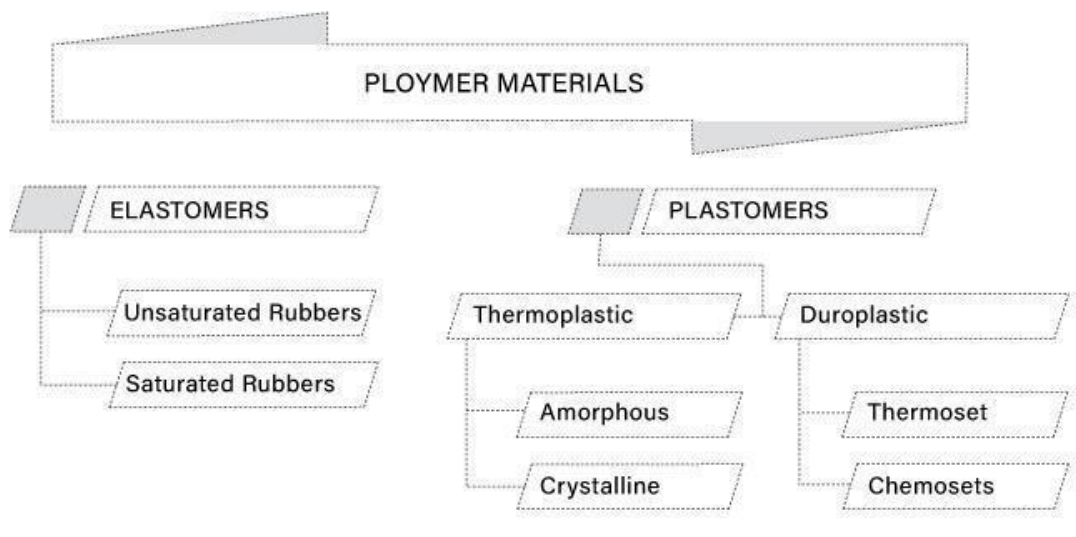

Figure 4. Once separated from other materials, polymers must be separated from each other. Figure adapted from (Flizikowski et al 2021). 
Once in separate bins or silos, each plastic must be shredded, usually through two or more machines that reduce the polymer to flakes that are small enough to wash, dry, and process in plastics molding equipment. These steps typically have automation; however, energy must be expended to cut the polymers and dry them with heat, as wet plastics cannot reach the process temperature without vaporizing the water and creating bubbles that weaken the new polymer products. Finally, the recycling center is not likely to be near the plastics producer and plastic shards in ton weights must be shipped. Often, the reclaimed polymer is shipped overseas.

\subsection{THE SYSTEM-LEVEL PROBLEM: A NETWORK OF WASTE}

Since the 1980's, China has been the largest consumer of global waste, importing materials from every developed country on the planet. Half of all global exports, 45 million tons equating to $\$ 18$ billion dollars in commodity value, were imported by China in 2016 (Rico 2018). However, in an effort to protect their own environment, China implemented the "National Sword" policy in January 2018, banning 24 different materials, with a focus on plastics. They further announced in 2018 an intent to ban all waste imports by the year 2020 (Rico 2018). Reductions in waste export options are especially threatening to the US waste management network structure because it has historically relied heavily on Chinese demand to support the local recycling industry. The US reports that approximately $1 / 3$ of recycling commodities are exported outside the country (Rico 2018). The National Sword policy caused the 2018 US plastic recycling rate to drop from a national average of $9.1 \%$ to $4.4 \%$ (Dell $2018 \mathrm{~b}$ ) and it is estimated it will cause a global displacement of 111 million metric tons of plastic material waste by the year 2030 .

The change has forced management companies in the US waste network to rapidly adjust to losing this consumer for their recyclable materials. The loss has highlighted just how fragile the US waste and recycling network has been. The immediate patches have been slower processing (allowing for a more diligent
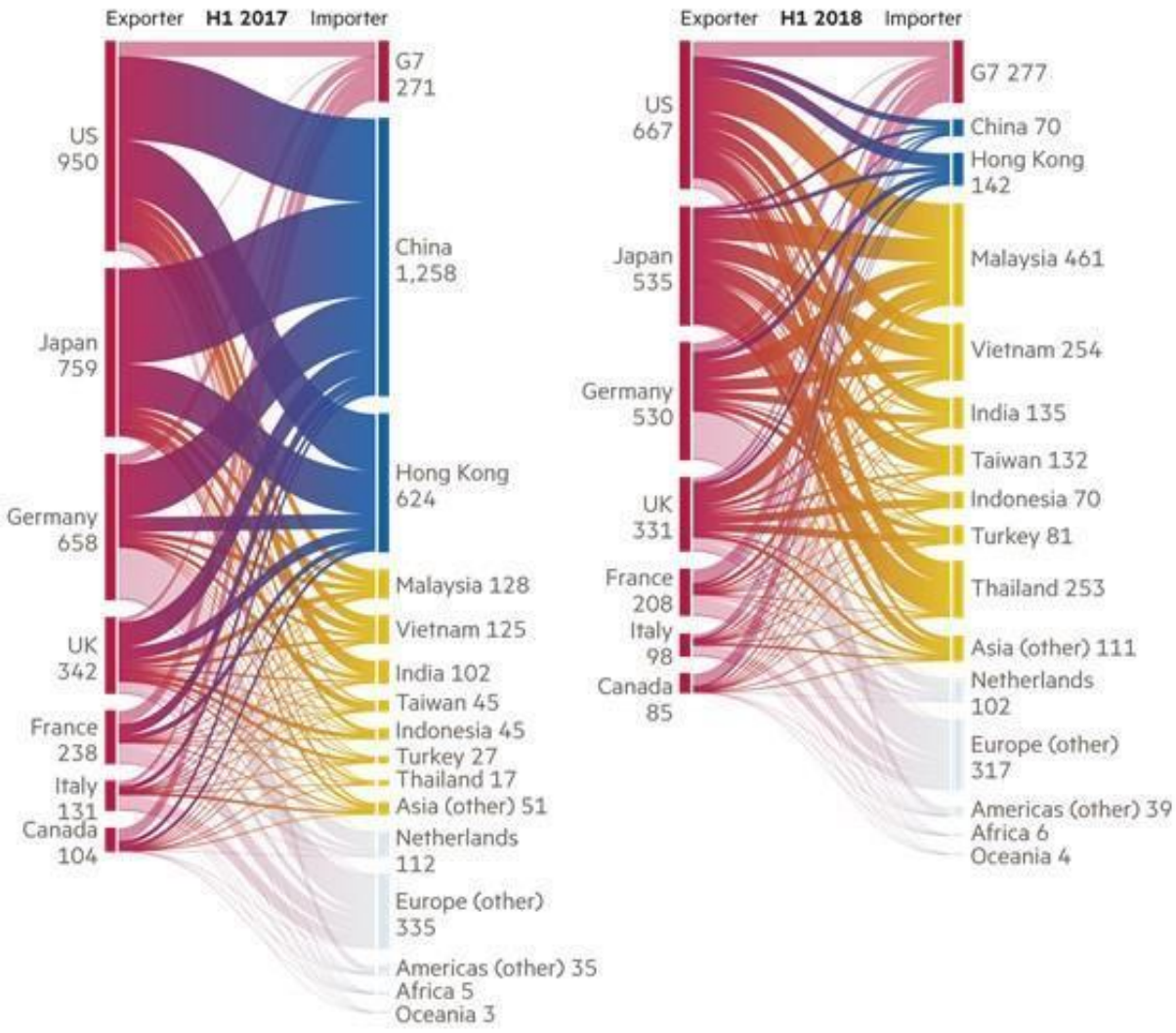

Figure 5. Global change in plastic waste before (left) and after (right) the Chinese crackdown on plastic waste imports known as the "National Sword." Figure from (Blood, Faunce, and Rininsland 2018). 
sorting to meet the new exportation standards set for recycling commodities), upgraded processing technology, finding new markets (Malaysia, Thailand, Vietnam), stockpiling, incineration for gas recovery (also known as waste to energy), and increased landfilling (Rico 2018). An unfortunate result has been a spike in imports by alternative Asian countries. Places like Malaysia, Vietnam, Taiwan, and Thailand have been overwhelmed with a sudden glut of materials (see Figure 1), spurring many of these countries to implement their own importation bans (Lee 2019, Parker 2018). Reports estimate that the recycling rate for materials like plastic may fall as low as 2.9\% in 2019 as the rest of Southeast Asia follows in China's footsteps (Dell 2018b).

Understanding the true impacts that losing exportation will have on the US waste management system and plastics recycling is not simple. The numbers reported by the US Environmental Protection Agency (EPA) are assumed to represent all US waste generation, however these values only represent municipal solid wastes (MSW), which only make up roughly $30 \%$ of the actual US values (Williams 2019). An absence of uniform terminology, confusion surrounding the roles of federal and local governments, and an inadequacy of enforcement standards all contribute to a considerable amount of waste going unreported in national MSW totals (Offenhuber et al. 2012). Each state handles their waste management independently (adhering to a few EPA national regulations), limiting access to information and the ability to analyze and address problems at a national level. An impactful and circular economy (CE) design solution, one that alleviates the challenges introduced by both limited resources and excess waste generation (Laird 2017), requires a system level model that considers the many components making up the US waste network.

The EPA published recycling rate at $25.8 \%$, not including compost material (US EPA 2018) but including scrap material sold as an export commodity. This approach inflates recycling numbers by counting sold exports as recycled material, an approach taken by more than just the US. Figure 6 illustrates the percentage of total plastic waste that is mismanaged by countries around the world. These inadequate waste management practices include landfill disposal, which when open and uncontrolled has a high likelihood of polluting rivers and oceans. Figure 6 does not consider littered waste, which makes up approximately $2 \%$ of total waste of low- and high-income countries. Countries advertising a $0 \%$ share of mismanaged waste in Figure 6 are also the primary exporters of plastic scrap material in Figure 5. Eight of the nine

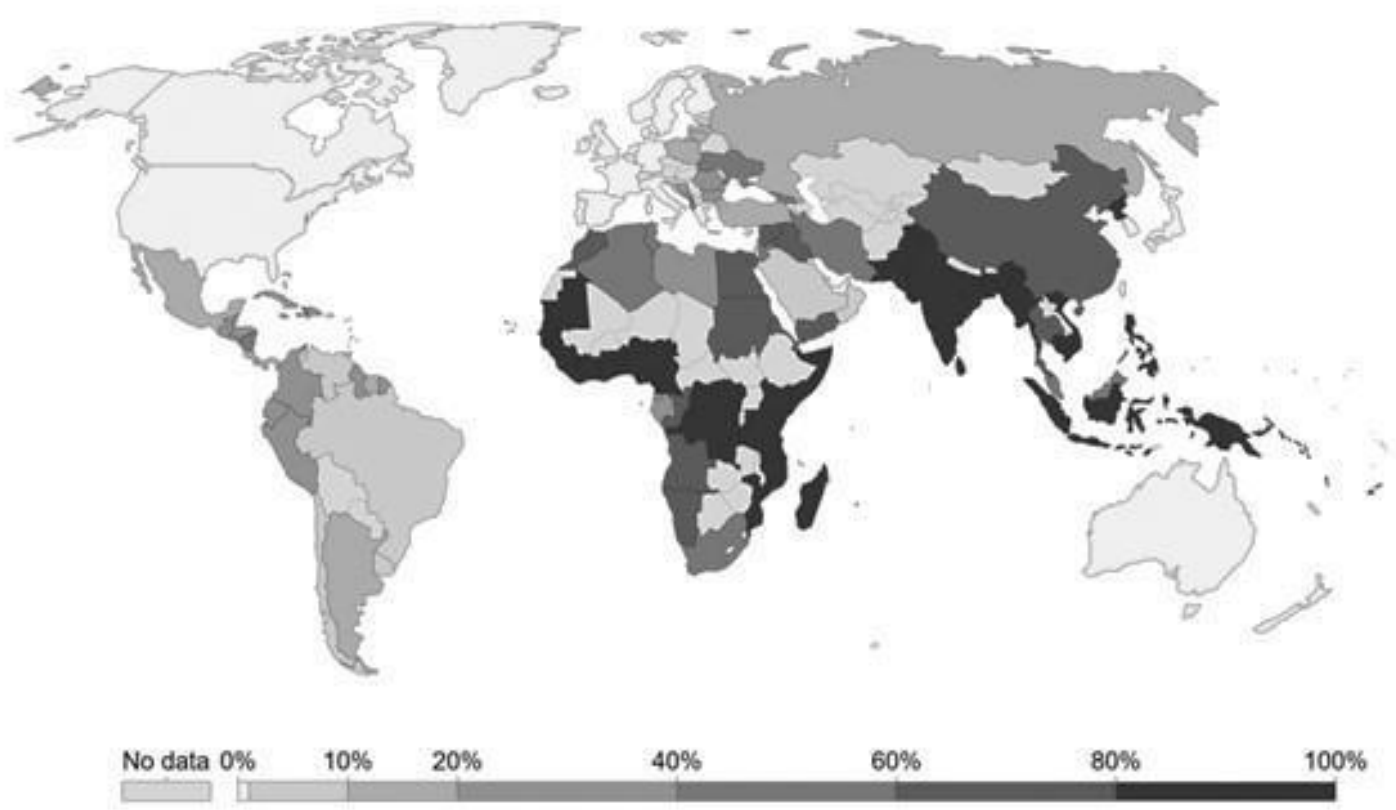

Figure 6. The percent inadequately managed plastic worldwide in 2010. Darker colors represent a higher percentage mismanaged and lighter colors represent a lower percentage. Grey signifies that no data was available. Figure adapted from Jambeck et al. (2015). 
largest exporters of plastic waste in 2018 reported 0\% mismanaged waste in the study generating Figure 6 (ISRI 2019, Jambeck et al. 2015): in 2018, for example, the US reported 0\% mismanaged waste but sent $78 \%$ of its plastic waste to countries who had a greater than 5\% mismanagement rate (Dell 2018a). The main importers of materials with a low market price on recycled products, for example paper and plastic, were among the counties with the highest percentage of mismanaged waste.

\begin{tabular}{|cc|}
\hline Country & $\begin{array}{c}\text { \% Mismanaged } \\
\text { Waste }\end{array}$ \\
\hline Malaysia & $55 \%$ \\
Thailand & $73 \%$ \\
Vietnam & $86 \%$ \\
India & $85 \%$ \\
China & $74 \%$ \\
\hline
\end{tabular}

Table 1. Primary US plastic export destinations and their mismanaged waste rates (Jambeck et al. 2015).
Table 1 shows the mismanagement rates for some primary destinations for US exported waste in 2017 and 2018 (ISRI 2018b, Jambeck et al. 2015). The countries listed account for (at a minimum) $44.9 \%$ of the annual US plastic exports and $72 \%$ of US global plastic exports from January to June of 2018 (Clark and Howard 2018, Dell 2018a). The values are likely even higher, as both Mexico and Canada also imported US plastic and waste that gets sent overseas (Dell 2018a). Table 2 shows countries' mismanagement rates and their volume of imported plastic waste from the US. The exportation values shown are for the months January to June 2018, thus these volumes represent only half of the year's US exports. Using the volume of exports and each receiving country's mismanagement rate (Table 2), it can be conservatively estimated that the US mismanaged 596,565 metric tons of plastic waste from January to June 2017 and 340,938 metric tons from January to June 2018 via its exports. According to this analysis, the US inadequately discarded more plastic in the first half of 2017 than it processed domestically for all of 2017 (466,929 tons (ISRI 2018a)) despite reporting a waste mismanagement rate of $0 \%$. With this information, is it fair to report that the US mismanagement rate is $0 \%$ ? Improving processing of plastics at their end of life must involve addressing the systemic issues associated with overall waste management.

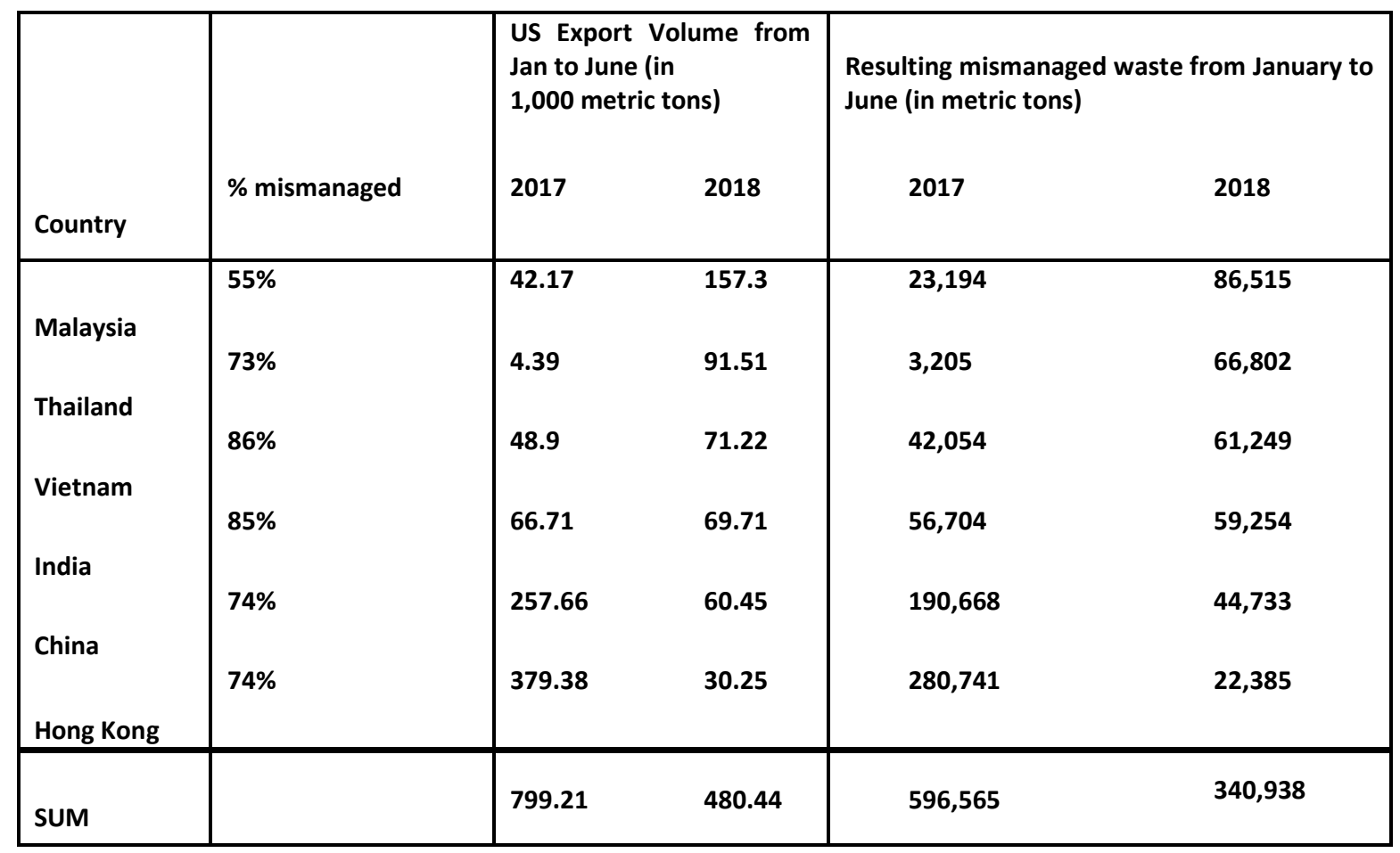

Table 2. US mismanaged volume of plastic waste by country for January to June 2018 (ISRI 2018c, Jambeck et al. 2015). 
With exportation lost as an option for plastics, some reports have determined that 211 million tons of plastic waste will be displaced by the year 2030 (Dell 2018b). Without an alternative destination and if the values for production and consumption remain the same, landfilling rates within the US can be expected to increase dramatically in the years following 2018's National Sword Policy. Recycling companies who previously sent their plastic material to Asia reported up to $100 \%$ of their material streams needed to be diverted directly to landfill wherever their operations were not supported entirely through government funding (Leinfelder 2019).

\subsection{OPPORTUNITIES AND SOLUTIONS}

As a research and a design problem involving science, engineering, social science, and aesthetics, plastic recycling compels us to examine the relationship between research and design. Its solution will not only derive from research, an analytical process that identifies a problem and discovers why the problem exists, but also result from design as "a purposeful and creative process in which means to an end is laid down" (Kepes 1951), one that always includes ways to address the problem in question. Furthermore, research and design work are integral to one another when plastic recycling is the issue. Thus, intuition and analytical thinking, which natural to research, are both essential to design. A purely intuitive response to a stimulus is at the best art but not design. Conversely, as formulating a research question and the methodology is a design process by itself, research does not exist without the design component. Therefore, the second half of this paper will focus on solutions that move beyond understanding the resistance in plastic recycling and propose means to address the resistance.

\subsection{Redesign Design}

In the context and demand of plastic recycling, design transforms into an interdisciplinary and collective process beyond the focus on an object's form and appearance. We need to design with a recycling mentality so that any designed objects or products are no longer the end point but only a phase of a design to be transformed into. The frustrations in current plastic recycling reveal themselves more as industrial and policy problems rather than consumer problems. conditions. A designer needs to understand material potentials, manufacturing processes, and economic implications, and incorporate them when designing a product. Similarly, material scientists, system designers, economists need to draw reasons from one another to propose new strategies, which are a design process by essence. Design research will be based on a synergetic multidisciplinary framework. Each component in the framework-material research, systems studies, design and fabrication, and operational model testing-will provide feedback to others until feasible solutions and strategies are established.

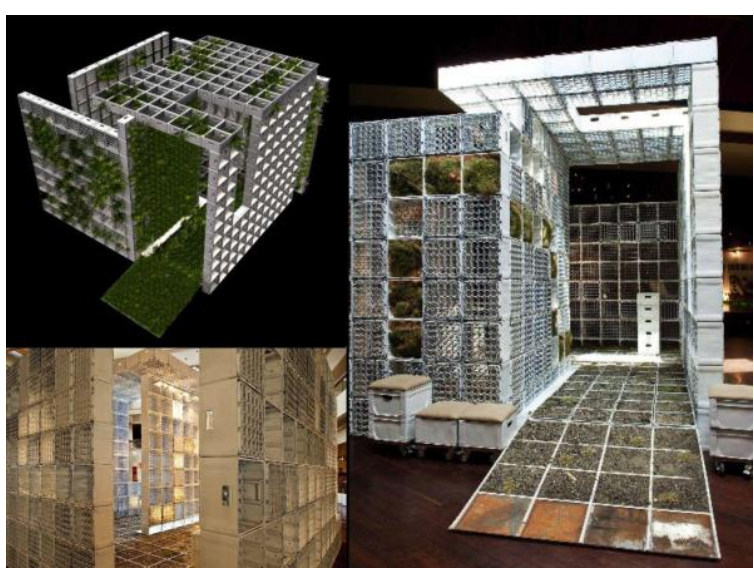

Figure 7. "Cecin'est pas un Container," author's proposal for a Pavilion "Living in Green Exhibition."

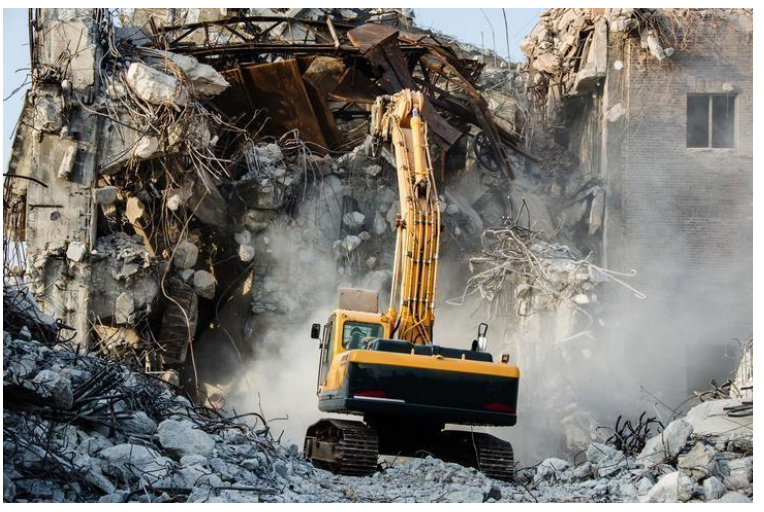

Figure 8. Dismantling of buildings (UMACON 2017).

Additionally, design is no longer acting with given conditions but is suggesting and creating new 

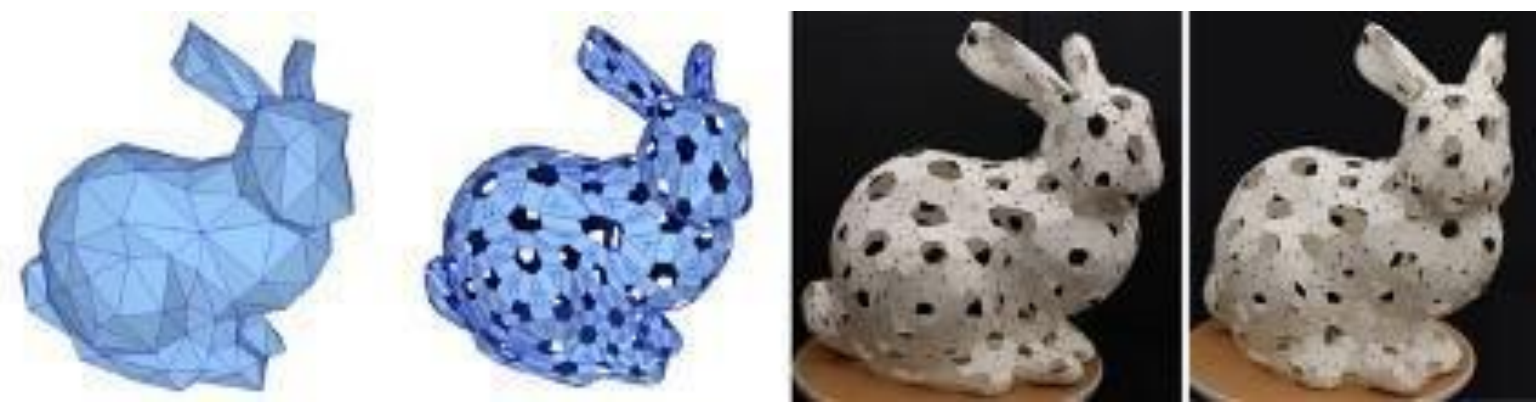

Figure 9. An example demonstrating the power of our method to construct any shape with similar panels.

As plastic have permeated our lives on multiple scales, the design response to recycle plastic needs to happen in a multi-scalar mode. On the object scale, plastic recycling reintroduces the conceptual modular design model or kit-of-parts in a contemporary context. For instance, The Gifts, published by Friedrich Fröbel in 1838-1840, contains playing blocks and rules that stimulate children's spatial imagination. The creative mechanism lies in numerous combinatorial possibilities based on a limited vocabulary and rule set. Froebel's building gifts are widely referenced and adopted as a design concept and strategy. Frank Lloyd Wright attributed to it his early childhood discovery of architecture design. In 1982, George Stiny also referenced The Gifts when establishing his computational design method Shape Grammars.

Providing a vocabulary and rules set and allowing the combinatory possibility to play has proven to be fruitful in stimulating design thinking. The kit-of-parts mentality allows easy replacement in an object, which leads to a design intention that positively facilitates recycling. For example, a proposal was made by the authors for a pavilion, Ceci n'est pas un container, that serves as a multi-purpose outdoor space. It comprises 742 plastic containers that function as load bearing architectural elements. The structure incorporates an irrigation system that passes through the existing holes in the containers, which allows natural vegetation to grow on the pavilion. This modular design also allows easy replacement of damaged components.

On the building scale, constructing the new and maintaining the existing has always led to the demand of new materials. In a global scheme, new building material consumption should arguably be limited to prioritize low-income countries' access to new materials to simplify their process in providing shelters and infrastructures. Is it possible to integrate
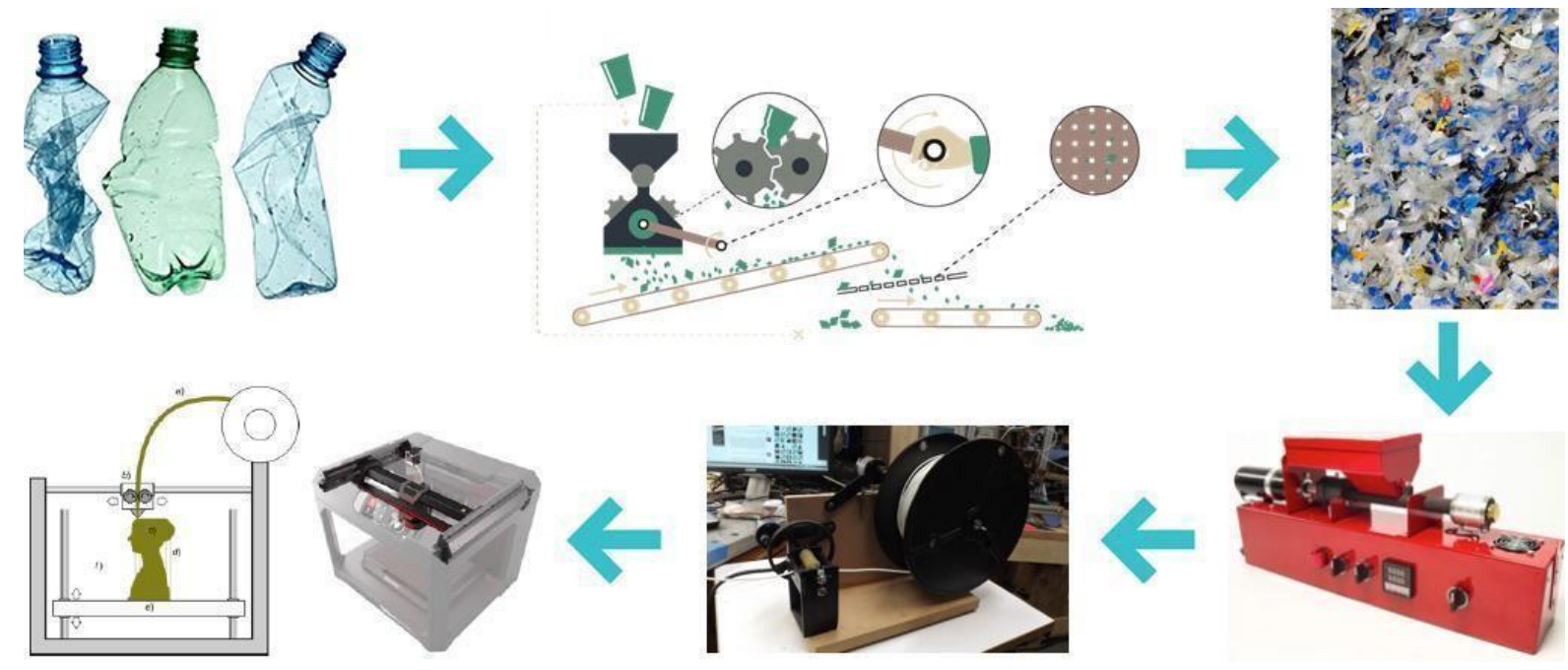

Figure 10. Workflow of integrating recycled plastics into additive manufacturing processes. 
recycled plastic into the currently dominant construction materials of lumber, concrete, and metal? As concrete is notoriously environmentally unfriendly, is it possible to create a new concrete with recycled plastics? Is it possible to extend plastic recycling to recycling construction materials? The constant amount needed for new materials in building construction opens an opportunity for plastic recycling.

According to the Steel Recycling Institute, in the United States almost $98 \%$ of steel in constructionwhere $70 \%$ is rebar embedded in concrete-is recycled. Concrete is recycled also, but with less market share and success. The US Geological Survey reports that the total raw material demand in construction is $70 \%$ aggregates, which are the rocks and sand added to cement to create concrete. Recycled concrete can be ground down into aggregates and used in new construction; however, only $5 \%$ of the aggregate market uses recycled concrete. In the current practice, concrete and plastic are combined to develop enhanced material properties. Plastic has a very low thermal conductivity, which significantly reduces its reaction to extreme temperature variations, which may in turn even improve concrete's endurance. Additionally, processed plastic can replace one essential component, sand, in concrete manufacturing. Recycled plastic is currently used in manufacturing concrete blocks for construction in all areas, especially low-cost housing in South American countries, such as Argentina, Ecuador, and Colombia. An even more audacious proposal would be to create a new concrete using recycled plastics and other recyclable materials.

Developing technology also offers opportunities in designing with recycling in mind. On an object scale, one can design complicated 2-manifold surfaces in modules. Ergun Akleman recently developed an unfolding system that provides many methods to convert any given computer-generated 2-manifold surface into panels that can physically be constructed with inexpensive materials (Hernandez 2013, Akleman 2016). Figure 9 shows a Computer-Graphics standard Bunny model physically constructed using his system. In this particular case, all the panels are simple trapezoids that can be packed very efficiently by significantly reducing the waste/unused material. The construction of the Bunny demonstrates the computer system's flexibility to transform complex surfaces into modules. Therefore, the old-fashioned kit-of-parts concept supports much variation in the output.
Furthermore, additive manufacturing presents unlimited variations that kit-of-parts cannot. If any geometry can be printed across the scales of an object and a building, design would have an improved ability to focus on individualized use. As a result, designing with plastic recycling relies even more on material science research than before. In current additive manufacturing, the principles of modular and kit-of-parts may still play a critical role in design due to constructability or printability of a component as well as the efficiency of assembly. But when the technology of additive manufacturing reaches the building scale, that is when a whole building can be printed, design will adopt a new framework that reflects such a construction process; and recycled plastic will be integrated in designs as a printable material and regain the polished quality that new material possesses.

Ultimately, design is a social action. New typologies that engage community and local government have demonstrated positive effects. For example, Ecoparks have improved recycling mechanisms. Ecoparks are waste management facilities that local communities access recover and process recyclable materials. They significantly reduce waste volume destined for landfills. Today, many Eco-parks operate in London, Barcelona, New York, Hong Kong, and other places with a positive impact in the recycling process. Local communities transport household discarded objects such as appliances, electronic waste, paper, cardboard, plastic bags, plastic containers, recyclable glass, metal, and more. Eco-parks also teach communities that recycling is important through workshops, information activities, and education programs with local schools. These activities present information for people at any age. The success of Eco-parks shows that, beyond designing for functional and aesthetic needs, design should also address mechanisms that engage the community. Design that operates with intervention addressing aesthetics to social actions should go hand in hand with recycling.

\subsection{Redesigning Material}

The first chemical discoveries that led to today's polymer economy were, like most technological discoveries, regarded by scientists and manufacturers as enablers for new industries that grew rapidly without regard to long-term consequences. Indeed, chemists tried to make polymers as long-lived and intractable as possible. Although this increased applications, markets, and profits, we know the outcome: polymer 
structures that survive for decades with little chance to be recycled into high performance components.

An exciting current development that could lead to a cyclic polymer material economy is work in dynamic polymers (Zheng 2021). Dynamic polymers are emerging chemistry with structures designed to accommodate recycling. These materials might improve the cyclic economy in two ways: self-healing and reduction to initial chemicals (Zhang 2021). With selfhealing polymers, constructions can extend their useful life by fixing flaws and cracks. With built-in recycling chemistry, polymers would no longer be destined to join a waste stream.

Figure 11 shows that almost $88 \%$ of each barrel pumped goes to transportation fuels. The remaining $12 \%$ provide a feedstock for plastics (4\%) and other petrochemicals (Hopewell 2009). As long as vehicles are fueled, this excess petroleum will be available for making plastics. This "fuel subsidy" keeps new plastics cheaper than recycled plastics as the industry gets income from fuel. There is a secondary subsidy at work as well. Plastics producers have not been charged with the costs related to plastics in the environment, which are estimated to range from $\$ 3,300$ per ton to $\$ 33,000$ per ton (Beaumont 2019). If plastics producers were charged with these costs, even with costs close to only $\$ 1000$ per ton, recycled plastic would become cheaper than new plastic.

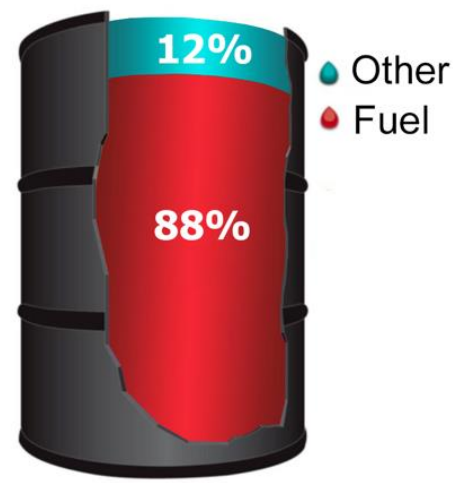

Figure 11. At 36 gallons per barrel of crude, gasoline, diesel, and other fuels have traditionally been the primary source for oil company income. Plastics, which are in the Other Products group in the diagram, have typically been subsidized by gasoline sales (energy.gov 2011).

\subsection{Redesigning Recycling from a System's Perspec- tive}

Losing China as the primary waste plastics recycler created a recycling network with many facilities unable to operate at a profit (Watson 2018, Hook and Reed 2018). New, stable customers for manufacturing by-products are needed to combat this loss, helping recyclable and reusable materials bypass the label "waste" (Williams, Warrington, and Layton 2019). Eco-Industrial Parks (EIPs, networks of industries connected via by-product reuse interactions) highlight the power of byproduct reuse. Industries in an EIP exchange materials and energy that would otherwise be disposed of, reducing raw material use and emissions at a system-level. The Kalundborg EIP in Denmark is a highly successful example, the last $50+$ years have seen the formation of mutually beneficial industry exchanges reducing carbon emissions by 240 kilotons/yr and freshwater usage by 264 million gallons/yr (Jacobsen 2006). Despite these impressive numbers however, reproducing this type of success has been difficult. Work that looked into EIPs' qualitative analogy with biology of "waste equals food" found that these networks often fail to replicate the characteristics that make biological ecosystems resilient and sustainable networks (Layton, Bras, and Weissburg 2016a, Layton, Bras, and Weissburg 2016b, Layton, Bras, and Weissburg 2016c). Work to translate these characteristics into implementable design guidelines has shown however that purposeful application can result in a network that improves its ability to extract all available value from any material and energy inside the network boundaries (Layton, Bras, and Weissburg 2016a, Layton, Bras, and Weissburg 2016b, Layton, Bras, and Weissburg 2016c).

Comparing the US recycling network to biological food webs also highlights areas where value is lost and resilience can be improved. The latter is important for preventing another catastrophic network failure when a recycling customer is lost. Biological food webs have been found to be very good at reducing waste production (Malone et al. 2018, Layton, Bras, and Weissburg 2017). This property has been attributed to a strong presence of cyclic energy pathways within the system boundaries. These cycles are the result of species whose primary function is to break down low quality materials and energy to return it for use, known as detritivores (Townsend, Begon, and Harper 2008). The relative size of the arrows and boxes in Figure 12 provides insight into the importance of dead organic matter in food webs, 5 
times the magnitude of the other major energy exchanges (Townsend, Begon, and Harper 2008). Dead organic matter is processed exclusively by detritivores (e.g., earthworms, fungi, and bacteria). These species are exclusively able to reintroduce these lowquality flows back into the network (known as the detrital feedback loop). This process has been linked to the overall dynamics and stability of food webs (McCann 2012), their ability to support species diversity and larger predators (Moore et al. 2004), and an increase in efficient resource use (Halnes, Fath, and Liljenström 2007). Multiple feedback loops have also been found to have a stabilizing effect on the performance of the overall system (Moore et al. 2004). These insights suggest that recycling networks could be stabilized by looking to food webs and their use of low-quality energy flows. Circular economy's goal to minimize dependence on raw materials may also be addressed using food webs as inspiration. The connection between cyclic pathways and effective resource use/ability to endure resource scarcity (Ma and Kazanci 2014, DeAngelis et al. 1984) motivated increasing cycles in human networks that needed to

(a)

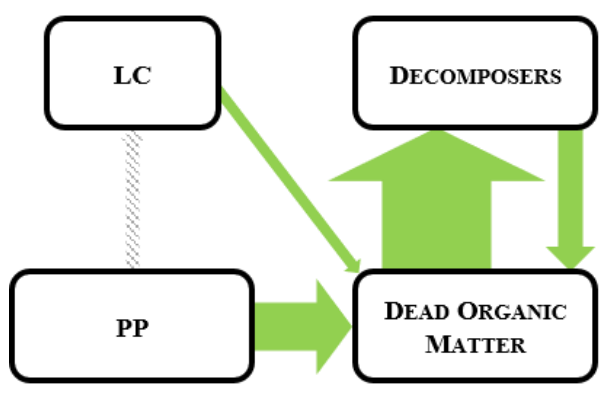

(c)

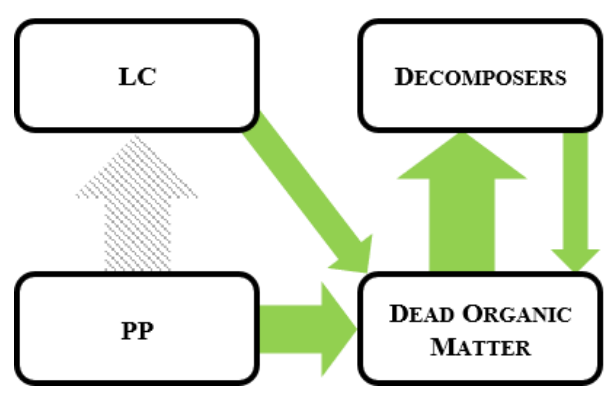

reduce their dependence on external resources (Scotti, Bondavalli, and Bodini 2009).

Ecological network analysis (ENA) has two metrics that can quantify the structural and functional aspects of cycling: cyclicity ( $\lambda_{\max }$, Eq. 1 where $\mathbf{F}$ is the matrix in Figure 13 (Layton et al. 2012, Fath and Halnes 2007, Layton, Bras, and Weissburg 2016b)) quantifies the presence and complexity of cycles, and Finn Cycling Index ( $\mathrm{FCl}$, Eq. 2 (Allesina and Ulanowicz 2004)) quantifies the proportion of matter flowing through the system that uses these cyclic pathways (Ma and Kazanci 2014). Cyclicity has the additional advantage that it only requires knowledge of the network structure, whereas $\mathrm{FCl}$ also requires knowing flow magnitudes (Layton et al. 2012).

$\lambda_{\max }=$ maximum real eigenvalue solution of: $\operatorname{det}\left|\mathbf{F}^{-1}-\mathbf{I}\right|$

$\mathrm{FCl}=$ sum of all flows that cycle/sum of all flows passing through the system (b)

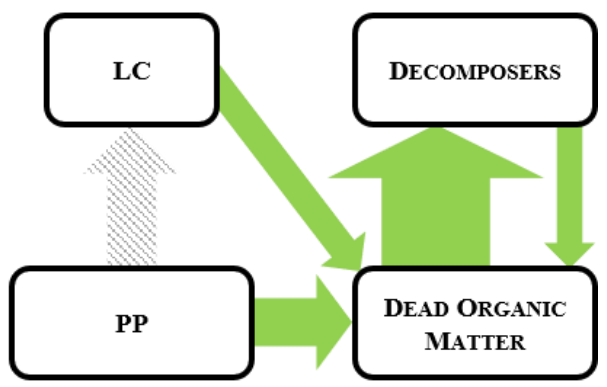

(d)

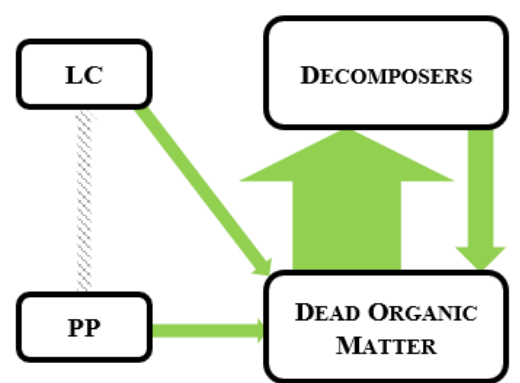

Figure 12. Relative magnitudes of the energy produced in and flowing between primary functional groups in four ecological networks: (a) Forest; (b) Grassland; (c) Plankton Sea Community; (d) Stream/Small Pond. General patterns of energy flow are indicated by the relative size of the boxes and arrows. Abbreviations: net primary production (PP); live consumer system (LC). Figure adapted from (Townsend, Begon, and Harper 2008). 
A lack of detritivore-analogous opportunities in industry is a challenge to mimicking these desirable food web characteristics (Williams, Warrington, and Layton 2019). Recognizing and adapting opportunities in industry, and in the larger national material network, would further the translation of these desirable properties of food webs (Malone et al. 2018, Layton, Bras, and Weissburg 2016b). Remanufacturing and recycling in industry currently focuses on breaking down byproducts into their basic parts so it can be used again to create a product of value in an analogous fashion to detritivores in food webs. The reuse of byproducts before it reaches a need to be recycled also falls into the analogous functional role of detritivores. Looking at the network representation of plastics recycling further confirms that the simple feedback recycling streams are analogous to the feedback streams of dead organic matter seen in ecological food webs.

The appendix covers the application of these metrics to plastics in the US. Flow-magnitude information is documented in Table A1 in the appendix, enabling the structure and functioning of each network to be quantitatively analyzed using cyclicity ( $\lambda_{\max }$, Eq. 1 and the matrix in Figure 13) and Finn Cycling Index ( $\mathrm{FCl}$, Eq. 2 and the matrix in Figure 13 coupled with flow magnitude values in Tables 2 and A1). A biologicallyinspired optimization of the plastic network using $\mathrm{FCl}$ was done in MATLAB (version R2016b) to illustrate what a bio-inspired system solution might look like for plastics recycling, the results of which are shown in Figure A1 in the appendix. The plastic waste values from Table 2 were used, but it must be acknowledged that these rates are optimistic values since plastic is much more likely than other imported wastes to be mismanaged due to the level of contamination involved in plastic waste as well as the low commodity price. An unfortunate amount of guesswork was also needed to create this "useful" network model of the US plastics recycling, reconfirming that addressing the US' plastics recycling problems is also hindered by a lack of information - "you can't manage what you don't measure (Hataway 2017)."

Optimizing the network to mimic the $\mathrm{FCl}$ values found in food webs suggests that enacting policies and practices that support reuse can have a strong positive impact. The inclusion of reuse (Figure A1-B) improves the cyclicity of the plastic network by increasing the retention of remaining value inside the system boundaries. This is also why the cyclicity of the network when exports are considered as part of the system results are higher (Table $\mathrm{A} 2$ in the appendix). When exports are inside the system boundaries the value lost when plastics are exported are not discernible, confirming that the current data reporting method used in the US disguises the lost value that occurs when plastics are exported. The cyclicity values of the US' advertised (considering exports) versus

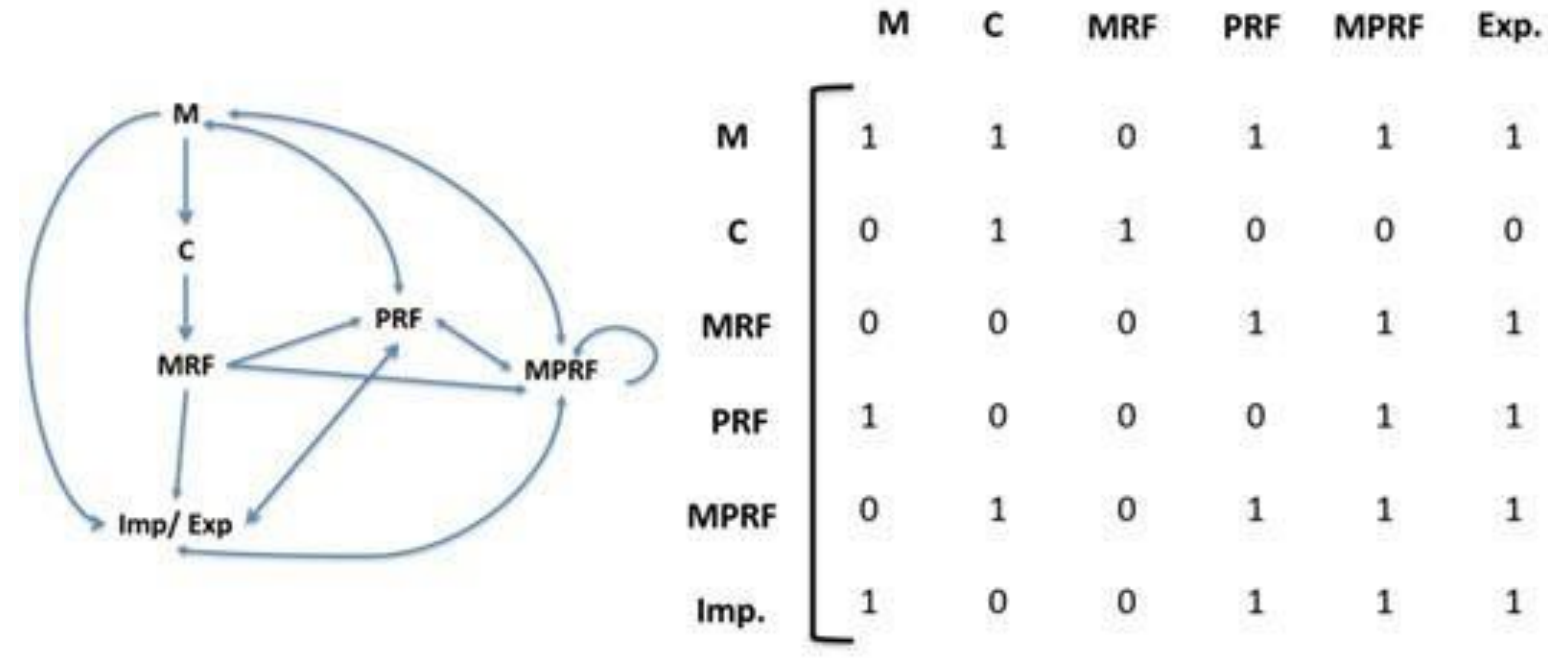

Figure 13. Material Flow Directional Graph (left) and Connectivity Matrix (right - connections indicated from row to column actor with a one) for Plastic Recycling (Williams 2019). Manufacturers (M); Consumers (C); Material Recovery Facility (MRF); Plastic Recovery Facilities (PRF); Manufacturers with Plastics Recovery (MPRF); Import of materials (Imp) or Export of recycled materials (Exp). 
actual (excluding exports) numbers demonstrates the gap between the US' advertised material recycling versus the actual. The results of this comparison coupled with the mismanaged waste rates support an overhaul of the US recycling network, both in terms of its functioning and data tracking/reporting.

Comparing the cyclicity values of the US' plastic network against what is seen on average in biological food webs (shown in Table A2) highlights the work that still needs to be done in order to adopt the stability and value retention that byproduct cycles confer to biological networks (Layton, Bras, and Weissburg 2016b, Layton et al. 2012, Williams, Warrington, and Layton 2019, Malone et al. 2018, Moore et al. 2004, Rooney et al. 2006). Investing in the development of additional processing facilities within the US, promoting additional methods of collection for recycled materials, and encouraging reuse (like the case study presented in (Ali et al. 2021)) and extending producer responsibilities are all routes that would support the capacity and prevalence of industries that could increase cycling towards the levels found in food webs.

\subsection{CONCLUSION: THE ACTION TAKERS}

Investigating resistance to plastic recycling, this article echoes Walter Stahel's work on Circular Economy, especially the differentiation between the " $R$ " (recuse, repair, remarket, remanufacture, re-refine, and reprogram) and the " $D$ " (de-polymerize, de-alloy, de-laminate, de-vulcanize, de-coat, and de-construct). The former happens on the object scale during the product use period while the latter occurs on an atomic or molecular scale after at the product's service life endpoint. The three perspectives in this article-design, material science, and systems-emphasize the " $R$," the " $D$," and their integration respectively. The goal of approaching plastic recycling as a design problem is to maximize the manufactured plastic objects. The goal of seeking potentials in material science to recycle plastics is to maintain the purity and quality of plastic as new resources. The goal of engineering new systems is to sustain the economic viability of plastic recycling.

Resistance on many levels of society still generates a fragmented, interrupted, and discontinuous process when dealing with recycling strategies. The US recycling system is based on three independent stages: collection, processing, and remanufacturing. Within the recycling structure there are numerous problems that distort the natural chain of the process, such as limitations associated with the selection and recollection process. One of the main issues is the lack of communication among the different sectors involved in the recycling of waste. Not only are there issues in the transformation process itself, but also in how the general population is incorporated into the process.

In all these approaches, the action takers, either as individuals or as groups, play various roles, such as the owner-user or owner-manager of used objects, the salesman or distributor, and the policy maker. These roles carry significant weight in decision-making and actions, influencing the attempts to recycle plastic and critically impacting the final results.

The inertia of plastic recycling deeply resides in the action taker's value system, specifically regarding convenience and profit. Choosing plastics as an industrial material in the first place is due to its cheap cost and high productivity. These choices can only be reversed by addressing action takers' value system. In the long term, we may not be able to sacrifice convenience and profit but can require that action takers accept responsibility. Recycling will most likely remain a needed component on the global journey to zero waste, along with reuse and a radical change in both producer and consumer habits. Therefore, although many argue (with reason) that recycling cannot be the sole focus, identifying routes to improve recycling, and more specifically plastics recycling, remains of critical importance. While the current backlog of waste must be addressed by all measures, from cooperative, local repurposing to regional and global reuse, suppliers must be guided, through policy and social influence, to reduce production of typical polymers and to support research of the novel chemistries working towards new polymers that are as recyclable as metals.

Fundamentally, we design with people and for people. Meaningful community engagement builds the foundation of sustaining plastic recycling efforts. Design itself will gain more livelihood if it addresses both social and cultural issues. Figure 14 illustrates a recent design proposal by the authors outlining strategies to 3D print outdoor furniture and playground equipment with recycled plastics to revitalize neglected public spaces. The design can be developed into a modular system to respond to varied needs in communities. This is just one example of how plastics recycling and reuse, when purposefully coupled with design, can connect, engage, and benefit people both 
directly in their daily lives, as well as indirectly by reducing plastic waste.

Continued technology development can result in portable plastic recycling systems that will produce refined objects to be immediately used in everyday life, maintaining avenues for convenience and profit. Such tools will enable individuals to conduct their own plastics recycling without relying on the industrial production chain and evolve the habit of sorting recycled plastics into a creative process that enriches people's lives. Broad, publicly accessible dissemination of plastics-related research outcomes and design examples are needed to support these activities. Furthermore, portable plastic recycling systems can be provided as a service, which could create a meaningful social business opportunity.

The challenge of plastic recycling certainly has brought forth a series of unanswered aesthetic, economical, ethical, and philosophical questions. Is the action of recycling intrinsically beautiful? Is it sustainable to sacrifice the economy for recycling? What is the philosophical root of the balancing the value of recycling and convenience and profit? How can strategies be catered to specific social groups to reinforce and expand recycling? How can architecture and design contribute to erasing resistance from social and economic policies and production? Ultimately, should we completely eliminate the production and use of plastics? These questions suggest many possibilities and uncertainties. However, we have one certainty: we have been producing plastics for more than a century, and recycling is now our unavoidable mission. To fulfill this mission, we must make recycled plastics part of new creative processes, resources, and opportunities. Only when this happens will resistance diminish.

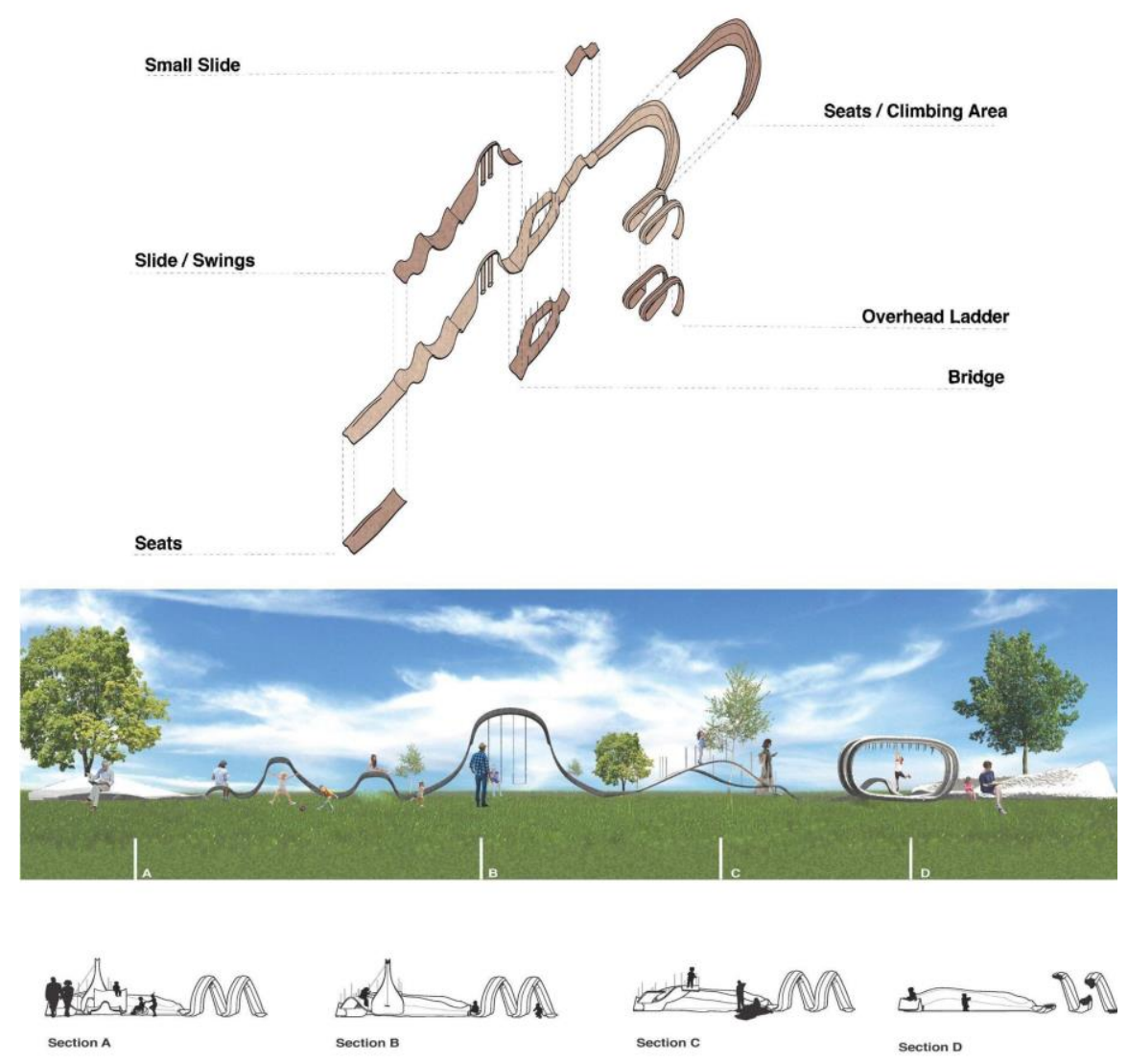

Figure 14. A design proposal integrating plastic recycling with social impacts, highlighting strategies to 3D print outdoor furniture and playground equipment with recycled plastics to revitalize neglected public spaces. 


\section{References}

Ali, Ahmed, Astrid Layton, Patricia Kio, and Jewel Williams. 2021. "Matrix Trays: From Waste to Opportunities " Journal of Cleaner Production 300. https://doi.org/10.1016/j.jclepro.2021.126813

Allesina, S., and R. E. Ulanowicz. 2004. "Cycling in ecological networks: Finn's index revisited." Computational Biology and Chemistry 28 (3):227-33. https://doi.org/10.1016/i.compbiolchem.2004.04.002

Beaumont, Nicola J., Margrethe Aanesen, Melanie C. Austen, Tobias Börger, James R. Clark, Matthew Cole, Tara Hooper, Penelope K. Lindeque, Christine Pascoe, and Kayleigh J. Wyles. 2019. "Global ecological, social and economic impacts of marine plastic." Marine Pollution Bulletin 142:189-195.

https://doi.org/10.1016/j.marpolbul.2019.03.022

Blood, David, Liz Faunce, and Andrew Rininsland. 2018. How the global river of plastic waste changed course in just 12 months. Financial Times Magazine: Financial Times.

Cecilia, Casado. 2018. "Los pies en el suelo." Last Modified November 19, 2018, accessed April 30, 2021. https://tinyurl.com/t3ner5et.

Cecon, Victor S., Paulo F. Da Silva, Greg W. Curtzwiler, and Keith L. Vorst. 2021. "The challenges in recycling post-consumer polyolefins for food contact applications: A review." Resources, Conservation and Recycling 167. https://doi.org/10.1016/j.resconrec.2021.105422

Clark, Joe S., and Emma Howard. 2018. "US plastic waste is causing environmental problems at home and abroad." Greenpeace, Last Modified May 10, 2018, accessed May 14. https://www.statista.com/statistics/892470/us-exports-plasticwaste-by-country/.

Cunha, S. M., A. Gaspar-Cunha, and J. A. Covas. 2009. "Melting of polymer blends in single screw extrusion - An experimental study." International Journal of Material Forming 2 (SUPPL. 1):729-732. https://doi.org/10.1007/s12289-009-0600-z

da Silva, Daniel Jose, and Helio Wiebeck. 2020. "Current options for characterizing, sorting, and recycling polymeric waste." Progress in Rubber, Plastics and Recycling Technology 36 (4):284-303.

https://doi.org/10.1177/1477760620918603
DeAngelis, D. L., S. M. Adams, J. E. Breck, and L. J. Gross. 1984. "A stochastic predation model: Application to largemouth bass observations." Ecological Modelling 24 (1):25-41. https://doi.org/10.1016/0304-3800(84)90053-X

Dell, Jan. 2018a. "157,000 Shipping Containers of U.S. Plastic Waste Exported to Countries with Poor Waste Management in 2018." Plastic Pollution Coalition, Last Modified March 6, 2019, accessed May 14. https://www.plasticpollutioncoalition.org/pft/2019/3/6/157000shipping-containersof-us-plastic-waste-exported-to-countries-withpoor-wastemanagement-in-2018.

Dell, Jan. 2018b. "U.S. Plastic Recycling Rate Projected to Drop to $4.4 \%$ in 2018." Plastic Pollution Coalition, Last Modified October 4, 2018, accessed April 4.

www.plasticpollutioncoalition.org/pft/2018/10/4/us-plastic-recycling-rate-projected-todrop-to-44-in-2018.

Donovan, Tara. 2009. "Frieze." Last Modified March 12, 2009, accessed April 30, 2021.

https://www.frieze.com/article/tara-donovan.

Energy.gov. 2011. "The How's and Why's of Replacing the Whole Barrel." Last Modified October 19, 2011, accessed April 30, 2021. https://www.energy.gov/articles/hows-and-whysreplacing-wholebarrel.

EPA. 2021. "The U.S. Recycling System." USA, accessed April 30,2021. https://www.epa.gov/americarecycles/us-recycling-system.

Eriksen, M. K., K. Pivnenko, M. E. Olsson, and T. F. Astrup. 2018. "Contamination in plastic recycling: Influence of metals on the quality of reprocessed plastic." Waste Management 79:595-606. https://doi.org/10.1016/j.wasman.2018.08.007

Fath, B. D., and G. Halnes. 2007. "Cyclic energy pathways in ecological food webs." Ecological Modelling 208 (1):17-24.

https://doi.org/10.1016/j.ecolmodel.2007.04.020

Flizikowski, Jozef, Weronika Kruszelnicka, and Marek Macko. 2021. "The development of efficient contaminated polymer materials shredding in recycling processes." Polymers 13 (5):1-44.

https://doi.org/10.3390/polym13050713 
Hakkens, Dave. 2020. "Precious plastic." Last Modified 2020, accessed April 30, 2021.

https://davehakkens.nl/projects/precious-plastic/.

Halnes, G., B. Fath, and H. Liljenström. 2007. "The modified niche model: Including detritus in simple structural food web models." Ecological Modelling 208 (1):9-16.

https://doi.org/10.1016/j.ecolmodel.2007.04.034

Hataway, James 2017. "More than 8.3 billion tons of plastic made: Most has now been discarded." Science News, accessed April 29. https://www.sciencedaily.com/releases/2017/07/170719140939.htm.

Hernandez, Peraza, Edwin A., Darren J. Hartl, Ergun Akleman, and Dimitris C. Lagoudas. 2016. "Modeling and analysis of origami structures with smooth folds." Computer-Aided Design 78:93-106. https://doi.org/10.1016/j.cad.2016.05.010

Hook, L., and J. Reed. 2018. Why the World's Recycling System Stopped Working. Financial Times.

Hopewell, Jefferson, Robert Dvorak, and Edward Kosior. 2009. "Plastics recycling: challenges and opportunities." Philosophical transactions of the Royal Society of London. Series B, Biological sciences 364 (1526):2115-2126. https://doi.org/10.1098/rstb.2008.0311

ISRI. 2018b. "2017 U.S. Scrap Exports by Major Commodity." Institute of Scrap Recycling, Inc., accessed May 14. https://www.isri.org/recycling-commodities/international-scrap-tradedatabase/2017-tradeflows.

ISRI. 2018c. Volume of Plastic Scrap Exports from The United States in 2017, by Select Destination Country (in 1,000 Metric Tons). Statista - The Statistics Portal: Statista.

ISRI. 2019. Global Exports of Plastic Scrap by Country and Year. In Recycling Commodities: Institute of Scrap Recycling, Inc.

Jacobsen, Noel Brings. 2006. "Industrial Symbiosis in Kalundborg, Denmark: A Quantitative Assessment of Economic and Environmental Aspects." Journal of Industrial Ecology 10 (1/2):239-255.

https://doi.org/10.1162/108819806775545411

Jambeck, Jenna R., Roland Geyer, Chris Wilcox, Theodore R. Siegler, Miriam Perryman, Anthony Andrady, Ramani Narayan, and Kara Lavender Law. 2015.
"Plastic waste inputs from land into the ocean." Science 347 (6223):768-771.

https://doi.org/10.1126/science.1260352

Kepes, Gyorgy and S.I. Hayakawa 2012. Language of Vision. Chicago: Paul Theobald.

Kovacs, Robert, Anna Seufert, Ludwig Wall, HsiangTing Chen, Florian Meinel, Willi Müller, Sijing You.

"TrussFab: Fabricating Sturdy Large-Scale Structures on Desktop 3D Printers." In Proceedings of the 2017 $\mathrm{CHI}$ Conference on Human Factors in Computing Systems, pp. 2606-2616. ACM, 2017.

https://doi.org/10.1145/3025453.3026016

Kovacs, Robert, Anna Seufert, Ludwig Wall, HsiangTing Chen, Florian Meinel, Willi Müller, Sijing You et al. (2018) TrussFab Project Website. [Online]. Available at: hpi.de/baudisch/projects/trussfab.html (Accessed 17 April 2018).

Laird, Karen. 2017. "Exploring plastics' role in the future circular economy." Plastics Engineering (6):1219. https://doi.org/10.1002/j.19419635.2017.tb01725.x

Layton, A., B. Bras, and M. Weissburg. 2017. "Improving performance of eco-industrial parks." International Journal of Sustainable Engineering:1-10. https://doi.org/10.1080/19397038.2017.1317874

Layton, Astrid, Bert Bras, and Marc Weissburg. 2016a. "Designing Industrial Networks Using Ecological Food Web Metrics." Environmental Science \& Technology 50 (20):1124311252. https://doi.org/10.1021/acs.est.6b03066

Layton, Astrid, Bert Bras, and Marc Weissburg 2016b. "Ecological Principles and Metrics for Improving Material Cycling Structures in Manufacturing Networks." Journal of Manufacturing Science and Engineering 138 (10):101002-1 - 101002-12. https://doi.org/10.1115/1.4033689

Layton, Astrid, Bert Bras, and Marc Weissburg. 2016c. "Industrial Ecosystems and Food Webs: An expansion and update of existing data for eco-industrial parks and understanding the ecological food webs they wish to mimic." Journal of Industrial Ecology 20 (1):85-98.

https://doi.org/10.1111/jiec.12283

Layton, Astrid, John Reap, Bert Bras, and Marc Weissburg. 2012. "Correlation between Thermodynamic Efficiency and Ecological Cyclicity for 
Thermodynamic Power Cycles." PLoS ONE 7 (12):17. https://doi.org/10.1371/journal.pone.0051841

Lee, Bernie. 2018. Questions on Commodity Scrap. edited by Jewel Williams. N/A: N/A.

Lee, Yen Nee. 2019. "Malaysia, following in China's footsteps, bans imports of plastic waste." CNBC, Last Modified 25 Jan, 2019, accessed Mar 31.

https://www.cnbc.com/2019/01/25/climate-changemalaysia-following-china-bansplastic-waste-imports.html.

Leinfelder, Andrea. 2019. "Texas recyclers face challenges of weak demand, low prices." Houston

Chronicle, January 9.

https://www.reporternews.com/story/money/business/2019/01/14/texas-recycle-facechallengesweak-demand-low-prices/2569471002/.

Ma, Qianqian, and Caner Kazanci. 2014. "How much of the storage in the ecosystem is due to cycling?" Journal of Theoretical Biology 357:134-142. https://doi.org/10.1016/j.jtbi.2014.05.014

Malone, Stephen M., Abigail R. Cohen, Bert Bras, and Marc Weissburg. 2018. "The Application of Detrital Actors in Industrial Systems." Procedia CIRP 69:867871. https://doi.org/10.1016/i.procir.2017.11.091

McCann, Kevin S. 2012. Food webs, Monographs in Population Biology. Princeton, NJ: Princeton University Press.

Mollnitz, Selina, Michael Feuchter, Ivica Duretek, Gerald Schmidt, Roland Pomberger, and Renato Sarc. 2021. "Processability of different polymer fractions recovered from mixed wastes and determination of material properties for recycling." Polymers 13 (3):143. https://doi.org/10.3390/polym13030457

Moore, John C., Eric L. Berlow, David C. Coleman, Peter C. de Ruiter, Quan Dong, Alan Hastings, Nancy Collins Johnson, Kevin S. McCann, Kim Melville, Peter J. Morin, Knute Nadelhoffer, Amy D. Rosemond, David M. Post, John L. Sabo, Kate M. Scow, Michael J. Vanni, and Diana H. Wall. 2004. "Detritus, trophic dynamics and biodiversity." Ecology Letters 7 (7):584-600. https://doi.org/10.1111/j.1461$\underline{0248.2004 .00606 . x}$

Offenhuber, D., D. Lee, M. I. Wolf, S. Phithakkitnukoon, A. Biderman, and C. Ratti. 2012. "Putting matter in place." Journal of the American Planning
Association 78 (2):173-196.

https://doi.org/10.1080/01944363.2012.677120

Parker, Laura. 2018. "China's ban on trash imports shifts waste crisis to Southeast Asia." National Geographic, Last Modified Nov 16, 2018, accessed March 31. https://www.nationalgeographic.com/environment/2018/11/china-ban-plastic-trashimports-shifts-waste-crisis-southeast-asiamalaysia/.

Rico, Corinne 2018. "China's National Sword Policy: Impacts and Opportunities for U.S. Local Governments and Industry Stakeholders." Illinois Counties Solid Waste Management Association 26th Annual Conference, Illinois.

Rooney, N., K. McCann, G. Gellner, and J. C. Moore. 2006. "Structural asymmetry and the stability of diverse food webs." Nature 442 (7100):265-269.

https://doi.org/10.1038/nature04887

Roy, Nabarun, Eric Buhler, and Jean-Marie Lehn. 2014. "Double dynamic self-healing polymers: Supramolecular and covalent dynamic polymers based on the bis-iminocarbohydrazide motif." Polymer International 63 (8):1400-1405.

https://doi.org/10.1002/pi.4646

Scotti, Marco, Cristina Bondavalli, and Antonio Bodini. 2009. "Linking trophic positions and flow structure constraints in ecological networks: Energy transfer efficiency or topology effect?" Ecological Modelling 220 (21):3070-3080.

https://doi.org/10.1016/j.ecolmodel.2008.07.034

Sora News 24. 2014. Sora News 24, Last Modified June 5, 2014, accessed April 30, 2021. https://soranews24.com/2014/06/05/coca-cola-giving-awayspecialty-bottlecaps-invietnam-to-promote-reusingtheir-plastic-bottles/.

Tanenbaum, C. (2016) STEM 2026: A vision for innovation in STEM education. Washington, DC: US Department of Education.

Stahel, Walter R.. The Circular Economy: A User's Guide, Taylor \& Francis Group, 2019. ProQuest Ebook Central, https://ebookcentral.proquest.com/lib/tamucs/detail.action?do$\mathrm{clD}=5784306$.

Townsend, Colin R., Michael Begon, and John L. Harper. 2008. Essentials of Ecology. 3rd ed. Malden: Blackwell Publishing. 
UMACON. 2017. "Reutilizar materiales de construc-

ción después de una demolición." Last Modified September 13, 2017, accessed May 1, 2021. Image:

http://www.umacon.com/noticia.php/es/Reutilizarmateriales-de-construccion-despuesde-una-demolicion/440.

US EPA. 2018. Advancing Sustainable Materials Management: 2015 Fact Sheet.

Watson, S. K. 2018. "China Has Refused To Recycle The West's Plastics. What now?". NPR, accessed 31Oct. https://www.npr.org/sections/goatsandsoda/2018/06/28/623972937/china-has-refusedtorecycle-the-wests-plastics-what-now.

Williams, Jewel. 2019. "Opportunities of Applying System Analysis to the US Waste Management System: Bio-Inspired Solutions for a More Circular Economy." MS, Mechanical Engineering, Texas A\&M University.

Williams, Jewel, Shelby Warrington, and Astrid Layton. 2019. "Waste Reduction: A review of common options and alternatives." ASME 2019 14th International Manufacturing Science and Engineering Conference, Erie, PA, June 10-14.

https://doi.org/10.1115/MSEC2019-2903

Zhang, Qiang, Shujuan Wang, Bin Rao, Xingxing Chen, Li Ma, Chenhui Cui, Qianyun Zhong, Zhen Li, Yilong Cheng, and Yanfeng Zhang. 2021. "Hindered urea bonds for dynamic polymers: An overview." Reactive and Functional Polymers 159. https://doi.org/10.1016/j.reactfunctpolym.2020.104807

Zheng, Ning, Yang Xu, Qian Zhao, and Tao Xie. 2021. "Dynamic Covalent Polymer Networks: A Molecular Platform for Designing Functions beyond Chemical Recycling and Self Healing." Chemical Reviews 121 (3):1716-1745., https://doi.org/10.1021/acs.chemrev.0c00938 


\section{APPENDIX}

Data provided by the American International Scrap Trade Industries (ISRI, which acts as an aggregator of publicly available data) is pulled from the UN Comrade's database (Lee 2018). There is no governmental or private enterprise within the US responsible for tracking the production of material generation or recycling, especially in the case of recycling (Williams 2019). Reported US plastic production most often uses values published by the EPA, estimates that do not include construction or demolition waste or manufacturing waste streams, which is protected information by those private corporations (US EPA 2018). Table A1 is based on EPA information on consumption, ISRI information on the import and export of plastic scrap, and figures published from ISRI values for the total production of plastic (ISRI 2018c). These values only consider scrap imports and exports, representing a fraction of actual US plastic imports and exports. Data on production and consumption values are difficult to find and importation data, for example, is given in US dollars - making it difficult to determine volumes. Grey highlights in Table A1 are estimates from the EPA, of which the manufacturing production of plastics has the largest impact. As a whole however, the values in Table A1 enable a systems-level investigation of US plastic flows and the potential impacts of reuse.

The network described by Table A1 was optimized for Finn Cycling Index. The results suggest that enacting policies and practices that support reuse can have a strong impact (Figure A1-A and B show without and with respectively). The manufacturing with plastics recovery actor (actor 6 in Figure A1-A) is the only one with reuse. The cyclicity results of these two network designs, investigated with and without including exports as an actor, are shown in Table A2.

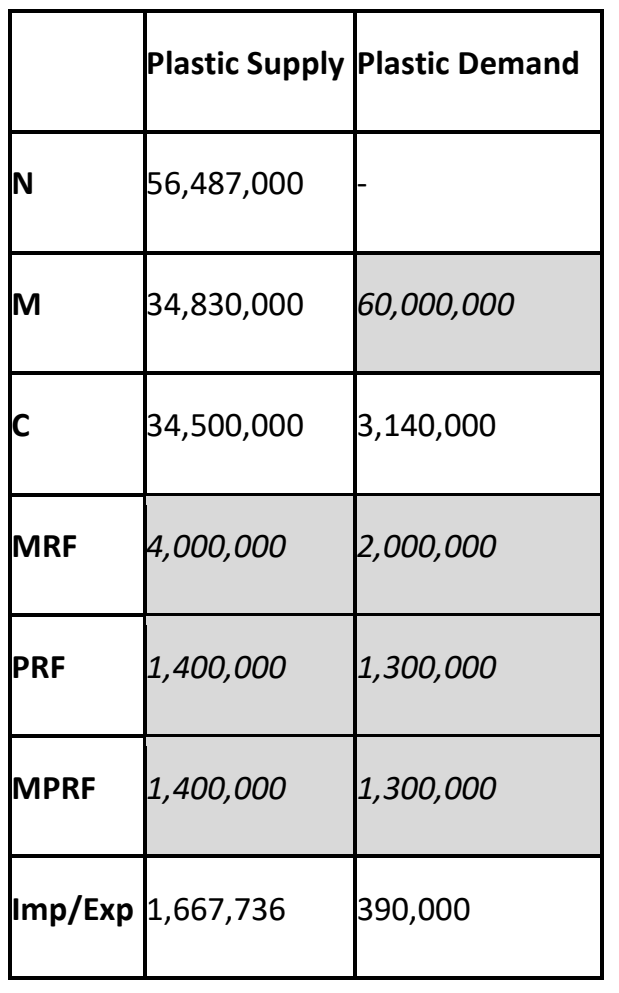

Table A1. US supply and demand values for plastic recycling (values are in metric tons) (Williams 2019). Greyed italic values are estimates. Production of New Plastics (N); Manufacturers (M); Consumers (C); Material Recovery (MRF); Plastic Recovery (PRF); Manufacturers with Plastics Recovery (MPRF); Imports/Exports of materials (Imp/Exp).

\begin{tabular}{|l|l|l|l|l|l|}
\hline \multirow{2}{*}{} & \multicolumn{2}{|l|}{$\begin{array}{l}\text { Considering Ex- } \\
\text { ports }\end{array}$} & \multicolumn{2}{|l|}{$\begin{array}{l}\text { Excluding Ex- } \\
\text { ports }\end{array}$} & \\
\cline { 2 - 5 } & $\begin{array}{l}\text { With } \\
\text { Re- } \\
\text { use }\end{array}$ & $\begin{array}{l}\text { With- } \\
\text { out Re- } \\
\text { use }\end{array}$ & $\begin{array}{l}\text { With } \\
\text { Re- } \\
\text { use }\end{array}$ & $\begin{array}{l}\text { With- } \\
\text { out Re- } \\
\text { use }\end{array}$ & FW \\
\hline $\begin{array}{l}\text { Cy- } \\
\text { clicity }\end{array}$ & 2.84 & 2.68 & 2.12 & 1.87 & 4.24 \\
\hline
\end{tabular}

Table A2. Resultant cyclicity values for the plastic recycling network optimized with and without reuse, for the network with and without exports included as an actor and compared to the average cyclicity of biological food webs (FW) (Williams 2019). 
(A)

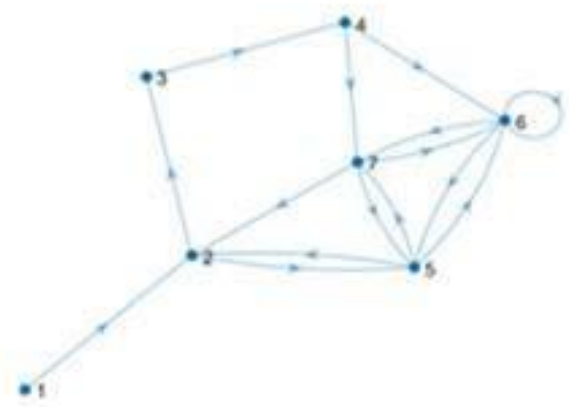

(B)

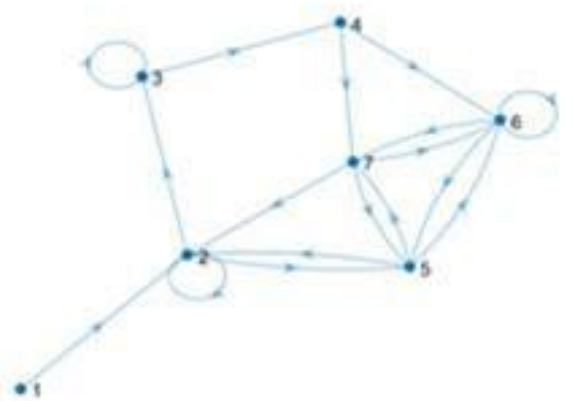

Figure A1. Optimized flow directional graphs for the US plastic recycling network without (A) and with (B) reuse (Williams 2019). The actors here are 1) primary production (new material, N), 2) manufacturer (M), 3) consumer (C), 4) material recovery (MRF), 5) plastic recovery (PRF), 6) manufacturing with plastics recovery (MPRF), and 7) import/export of plastic (Imp/Exp). 